\title{
MOTIVATIONAL FACTORS FOR SPORT: THE CASE OF SOCCER ATHLETES AGED BETWEEN 12 AND 17 YEARS
}

original paper

(C) University School of Physical Education in Wroclaw

DOI: https://doi.org/10.5114/hm.2018.77330

\section{NILVA PESSOA DE SOUZA ${ }^{1}$, HENRIQUE DE OLIVEIRA CASTRO ${ }^{2}$, JURACY DA SILVA GUIMARAES ${ }^{1}$, ARTHUR MOREIRA DO CARMO ${ }^{1}$, GUSTAVO DE CONTI TEIXEIRA COSTA ${ }^{1}$}

\author{
${ }^{1}$ Universidade Federal de Goiás, Goiânia, Brazil \\ ${ }^{2}$ Centro Universitário Estácio de Brasília, Taguatinga, Brazil
}

\begin{abstract}
Purpose. The purpose of the study was to identify the reasons why training athletes practise soccer, as well as verify changes in motivation in under-15 and under-17 athletes.

Methods. Overall, 100 male training athletes from a $2^{\text {nd }}$ division soccer club of the Brazilian Men's Soccer Championship in the state of Goiás participated in the research. The subjects were divided into 2 categories: under-14 (aged 12-14 years) and under-17 (aged 15-17 years). The mean age equalled $14.3 \pm 1.4$ years and the experience time was $10 \pm 4$ months. The instrument for data collection was the Motives for Physical Activity Measure - Revised scale.
\end{abstract}

Results. The results showed that the main reason for practising soccer was fun, followed by competence, fitness, social aspects, and appearance, successively $[\mathrm{F}(3,195,316,349)=60.036 ; p<0.05]$. However, when analysing the category of $12-14$ years, no difference was observed between the fun and competence dimensions, between competence and fitness, or between fitness and social aspects. The comparison between the categories proved that there were differences in appearance and social aspects dimensions, and that these aspects motivated more the athletes aged 15-17 years.

Conclusions. Consequently, the intrinsic motivation, specifically the reasons related to fun and competence, were the factors considered most important for soccer practice among young training athletes aged 12-17 years.

Key words: soccer, motivation, young

\section{Introduction}

Currently, the researches on soccer, specifically in relation to children and adolescents, focus on health, life quality, motor learning, psychosocial qualities, autonomy, and reasons for practising this sport [1-8]. Among these themes, motivational factors are the main aspects for the persistence of children and adolescents in team sport practices, specifically in soccer [1].

According to the theory of self-determination [9], the reasons that lead to sport practice can be extrinsic or intrinsic, and on this basis it is possible to determine the motivation for the sports practice. In this con- text, motivation is considered as the reasons that direct the behaviour of individuals when they participate in some experience, be it in sport, leisure, or work [10]. From that point, intrinsic motivation relates to internal personal factors, which refer to the individual's autonomy in making their choices according to the interest, pleasure, and satisfaction inherent to a particular sport activity or practice [9]. It is therefore possible to verify that intrinsic motivation is based on the aspects related to the fun and competence in the practice of sports [11]. On the other hand, extrinsic motivation relates to factors external to the subject such as the environment, coaches and parents - which

Correspondence address: Gustavo De Conti Teixeira Costa, Universidade Federal de Goiás, Cognição e Ação Lab., Faculdade de Educação Física e Dança, Campus Samambaia, Avenida Esperança s/n, Goiânia, Goiás, CEP: 74690-900, Brazil, e-mail: conti02@hotmail.com

Received: June 1, 2018

Accepted for publication: July 19, 2018

Citation: De Souza NP, Castro HO, Guimaraes JS, Carmo AM, Costa GCT. Motivational factors for sport: the case of soccer athletes aged between 12 and 17 years. Hum Mov. 2018;19(5)special/issue:8-13; doi: https://doi.org/10.5114/hm.2018.77330. 
allow specific results through behaviour driven by pressure or external rewards [9]. Extrinsic motivation shows itself related to social aspects, appearance, and fitness [12, 13].

In this context, motivation provides an understanding of the reasons why children and adolescents practise soccer, since it makes possible to gain knowledge about the reasons that initiate, regulate, sustain, direct, and interrupt the behaviour during the experience in this sport $[7,8,14]$. The literature of the area shows that sports practice is motivated by the autonomy, competence, performance, pleasure, and psychosocial skills of young athletes $[1,4,7,8,11,12,15,16]$. When analysing soccer, the reasons related to pleasure, motivational environment, and self-determined motivation $[10,17]$ are of greatest importance for practice, and Brazilian soccer athletes present the pleasure of playing this sport as their main reason for practising [14].

For that reason, among children and adolescents, the practice of soccer should be based on fun, the acquisition of motor skills and sports competences, consideration of the social relations with peers, parents, and coaches [3, 18]. In consequence, we hypothesized that the soccer athletes in training would be intrinsically motivated to practise this sport, with fun as the main reason. Therefore, knowing that the understanding of motivational factors allows to determine the adhesion to the sport practice [1], that there are differences in the motivation for soccer practice related to age [19], and that there is a gap in the literature on the motivation of young athletes, we aimed in the current study to identify the reasons why young training athletes practise soccer, as well as to verify changes in motivation in under-15 and under-17 athletes.

\section{Material and methods}

\section{Sample}

The total of 100 training athletes from a $2^{\text {nd }}$ division soccer club of the Brazilian Men's Soccer Championship in the state of Goiás participated in the research. All the participants were male. They were divided into 2 categories: under-14 (aged 12-14 years) and under-17 (aged 15-17 years). The mean age of the subjects was $14.3 \pm 1.4$ years and the experience time $10 \pm 4$ months. Of these athletes, $70 \%$ participated in regional competitions, $21 \%$ in state competitions, $3 \%$ in national competitions, and $6 \%$ in international competitions.

\section{Instrument}

The instrument for data collection was the Motives for Physical Activity Measure - Revised (MPAM-R) scale, translated into Portuguese and validated to the Brazilian context [20]. The scale presents 7 items that measure the fun dimension (e.g. pleasure, taste for practice, and happiness), 4 items that measure the competence dimension (e.g. like physical challenges and learn new skills), 6 items that measure the appearance dimension (e.g. improve appearance and attraction), 4 items that measure the fitness dimension (e.g. having more energy, improving cardiovascular condition, and maintaining physical health and well-being), and 5 items that measure the social dimension (e.g. meeting friends, liking the company of other people, and meeting new people).

The MPAM-R scale is composed of 26 items, each describing reasons for the sports activity, with the assigned numbers from 1 to 7 , where level 1 denotes 'nothing true for me,' and level 7 'totally true for me.'

\section{Procedures}

After presenting the purpose of the study and obtaining authorization to the data collection by having the terms of free consent signed by the athletes and their respective guardians, the questionnaires were applied at the beginning of a class by the responsible researcher in order to avoid an exalted emotional state and/or inattention caused by tiredness. The confidentiality of the answers was guaranteed, and the athletes were told that there was no right or wrong answer, so that they could answer sincerely. After that, the instructions were read, eventual questions were answered, and only then the athletes started to respond the questionnaires. If any doubts aroused, the researcher was called for help.

\section{Statistical analysis}

The analysis of the data was performed with the use of descriptive statistics: mean and standard deviation. It should be noted that weighted mean of the reasons for practising was applied, in accordance with the dimensions proposed in the instrument [20]. Thus, the dimensions were calculated by means of the following description:

1 - fun: $\left[\left(\mathrm{Q} 1^{*} 0.18\right)+\left(\mathrm{Q} 6^{*} 0.18\right)+\left(\mathrm{Q} 9^{*} 0.12\right)+\left(\mathrm{Q} 15^{*} 0.06\right)\right.$

$\left.+\left(\mathrm{Q} 19^{*} 0.16\right)+\left(\mathrm{Q} 22^{*} 0.12\right)+\left(\mathrm{Q} 25^{*} 0.18\right)\right]$

2 - competence: $[(\mathrm{Q} 2 * 0.26)+(\mathrm{Q} 3 * 0.14)+(\mathrm{Q} 7 * 0.30)+$ $\left.\left(\mathrm{Q} 11^{*} 0.30\right)\right]$; 


\section{HUMAN MOVEMENT}

N.P. Souza, H.O. Castro, J.S. Guimaraes, A.M. Carmo, G.C.T. Costa, Motivational factors for sport

3 - appearance: $\left[(\mathrm{Q} 4 * 0.13)+\left(\mathrm{Q} 8^{*} 0.19\right)+\left(\mathrm{Q} 14^{*} 0.21\right)+\right.$ $\left.\left(\mathrm{Q} 17^{*} 0.19\right)+\left(\mathrm{Q} 21^{*} 0.13\right)+(\mathrm{Q} 23 * 0.15)\right]$

4 - fitness: $\left[(\mathrm{Q} 10 * 0.18)+(\mathrm{Q} 13 * 0.27)+\left(\mathrm{Q} 16^{*} 0.27\right)+\right.$ $(\mathrm{Q} 20 * 0.28)]$;

5 - social aspects: $\left[(\mathrm{Q} 5 * 0.19)+(\mathrm{Q} 12 * 0.20)+\left(\mathrm{Q} 18^{*} 0.22\right)\right.$

$\left.+\left(\mathrm{Q} 24^{*} 0.16\right)+(\mathrm{Q} 26 * 0.23)\right]$.

Analysis of variance (ANOVA) with repeated measures was used to compare the dimensions, and the $t$-test for independent samples served to compare the groups. The level of significance was assumed at $p<$ 0.05 and the effect size (ES) was calculated by Cohen's $d$. The data collected were treated in the SPSS 20.0 (Statistical Package for the Social Sciences) software.

\section{Ethical approval}

The research related to human use has been complied with all the relevant national regulations and institutional policies, has followed the tenets of the Declaration of Helsinki, and has been approved by the authors' institutional review board according to the protocol of the Federal University of Goiás No. 2.667.526.

\section{Informed consent}

Informed consent has been obtained from all individuals included in this study and their legal guardians.

\section{Results}

The overall results show that the main reason for the soccer practice (Table 1) was fun, followed by competence, fitness, social aspects, and appearance, successively $[\mathrm{F}(3,195,316,349)=60.036 ; p<0.05]$.

The analysis of the reasons that lead athletes aged 12-14 years to the soccer practice shows the same tendency as the overall results: the main reason for the

Table 1. Overall means of motivational factors

\begin{tabular}{lcc}
\hline Dimension & Mean & $\begin{array}{c}\text { Standard } \\
\text { deviation }\end{array}$ \\
\hline Fun* & 6.4568 & 0.75259 \\
Competence $^{* *}$ & 6.0486 & 1.16795 \\
Appearance*** $_{\text {Fitness }}^{* * *}$ & 4.5613 & 1.52321 \\
Social aspects & 5.6865 & 1.41186 \\
\hline
\end{tabular}

* difference between the fun dimension and the other dimensions for $p=0.0001$

** difference between the competence dimension and the other dimensions for $p=0.0001$

*** difference between the appearance dimension and the other dimensions for $p=0.0001$

$* * *$ difference between the fitness dimension

and the other dimensions for $p=0.0001$
Table 2. Motivational factors for athletes aged $12-14$ years

\begin{tabular}{lcc}
\hline Dimension & Mean & $\begin{array}{l}\text { Standard } \\
\text { deviation }\end{array}$ \\
\hline Fun $^{*}$ & 6.3876 & 0.74850 \\
Competence $^{* *}$ & 5.8376 & 1.29213 \\
Appearance*** $^{* *}$ & 4.2268 & 1.67287 \\
Fitness $^{* * *}$ & 5.5420 & 1.57897 \\
Social aspects & 4.8498 & 1.58087 \\
\hline
\end{tabular}

* difference between the fun dimension and the other dimensions for $p=0.0001$

** difference between the competence dimension and the other dimensions, except the fitness dimension, for $p=0.0001$

*** difference between the appearance dimension and the other dimensions for $p=0.007$

*** difference between the fitness dimension and the other dimensions, except the competence dimension, for $p<0.02$

Table 3. Motivational factors for athletes aged $15-17$ years

\begin{tabular}{lcc}
\hline Dimension & Mean & $\begin{array}{c}\text { Standard } \\
\text { deviation }\end{array}$ \\
\hline Fun $^{*}$ & 6.5260 & 0.75783 \\
Competence** $^{* *}$ & 6.2596 & 0.99780 \\
Appearance $^{* *}$ & 4.8958 & 1.28874 \\
Fitness $^{* * *}$ & 5.8310 & 1.22132 \\
Social aspects & 5.6406 & 1.27703 \\
\hline
\end{tabular}

* difference between the fun dimension and the other dimensions, except the competence dimension,

for $p<0.004$

** difference between the competence dimension and the other dimensions, except the fun and fitness dimensions, for $p<0.001$

*** difference between the appearance dimension and the other dimensions for $p<0.001$

**** difference between the fitness dimension and the other dimensions, except the competence and social dimensions, for $p<0.017$

soccer practice (Table 2) was fun, followed by competence, fitness, social aspects, and appearance, successively $[\mathrm{F}(2,984,146,194)=35.086 ; p<0.05]$. However, there was no significant difference between the competence and fitness dimensions.

The analysis of the reasons that lead athletes aged 15-17 years to the soccer practice shows a tendency similar to the overall results: the main reason for the soccer practice (Table 3) was fun, followed by competence, fitness, social aspects, and appearance, successively $[\mathrm{F}(2,984,146,194)=35.086 ; p<0.05]$. How- 
Table 4. Comparison of motivational factors between groups

\begin{tabular}{|c|c|c|c|c|c|c|c|}
\hline Dimension & Age (years) & $n$ & Mean & $\begin{array}{l}\text { Standard } \\
\text { deviation }\end{array}$ & $t$ & $p$ & $E S$ \\
\hline \multirow{2}{*}{ Fun } & $12-14$ & 50 & 6.3876 & 0.74850 & \multirow{2}{*}{-0.919} & \multirow{2}{*}{0.36} & \multirow{2}{*}{0.009} \\
\hline & $15-17$ & 50 & 6.5260 & 0.75783 & & & \\
\hline \multirow{2}{*}{ Competence } & $12-14$ & 50 & 5.8376 & 1.29213 & \multirow{2}{*}{-1.828} & \multirow{2}{*}{0.07} & \multirow{2}{*}{0.18} \\
\hline & $15-17$ & 50 & 6.2596 & 0.99780 & & & \\
\hline \multirow{2}{*}{ Appearance } & $12-14$ & 50 & 4.2268 & 1.67287 & \multirow{2}{*}{-2.24} & \multirow{2}{*}{$0.027^{*}$} & \multirow{2}{*}{0.23} \\
\hline & $15-17$ & 50 & 4.8958 & 1.28874 & & & \\
\hline \multirow{2}{*}{ Fitness } & $12-14$ & 50 & 5.5420 & 1.57897 & \multirow{2}{*}{-0.289} & \multirow{2}{*}{0.31} & \multirow{2}{*}{0.10} \\
\hline & $15-17$ & 50 & 5.8310 & 1.22132 & & & \\
\hline \multirow{2}{*}{ Social aspects } & $12-14$ & 50 & 4.8498 & 1.58087 & \multirow{2}{*}{-2.752} & \multirow{2}{*}{$0.007^{*}$} & \multirow{2}{*}{0.27} \\
\hline & $15-17$ & 50 & 5.6406 & 1.27703 & & & \\
\hline
\end{tabular}

* difference for $p<0.05$

ever, there was no significant difference between the fun and competence dimensions, between competence and fitness, or between fitness and social aspects.

The comparison of the reasons that lead athletes to the practice of soccer (Table 4) shows that there were differences in the social aspects and appearance dimensions: these aspects motivated more the athletes aged $15-17$ years.

\section{Discussion}

The objective of the current study was to identify the reasons why training athletes practise soccer, as well as to verify changes in motivation in under-15 and under-17 athletes. The results showed that there were differences between fun, competence, fitness, social aspects, and appearance, which confirmed the initial hypothesis of the study. It was observed that the reasons related to intrinsic motivation, specifically fun and competence, were directly bound with the demand for practice of sports in athletes aged 12-17 years, as well as their persistence in it. These results corroborate studies in the area that prove the demand in young athletes for sport practice for fun, pleasure, and improvement of competences [11, 21, 22]. In this context, intrinsic motivation allows athletes to experience activities as if they were the originators of their own actions and chose to engage in that activity [9]. So, the sense of personal satisfaction, competence, and achievement makes intrinsic motivation relevant to the athletes [8], maintaining their adherence to trainings, which frequently do not present external rewards and demand high intrinsic motivation [23].
The analysis of the extrinsic reasons proved that the social aspects and fitness were less motivating for the practice of the sport, probably because they do not directly predict pleasure of playing sports or the acquisition of competences for it. However, studies in the field of sports psychology show that the persistence in the practice of sports depends on extrinsic reasons, such as relationship with peers and coaches, level of training requirement, and improvement of life quality $[15,16,24,25]$. So, it can be seen that the extrinsic reasons, although they present themselves as less motivating for sports, exert a positive impact on the personal and sports development in the young athlete, as well as are necessary for the improvement of psychomotor skills and for the internal and external social team relationships [26].

When comparing athletes aged 12-14 years with the ones aged 15-17, we observed that there were differences in the social aspects and appearance dimensions; these aspects motivated more the athletes aged 15-17 years. These results are in line with studies of the area which demonstrate, in young people aged 15-17 years, that sport practice promotes a more positive body image, stimulating athletes to contemplate their bodies, with reference to their functionality rather than beauty $[27,28]$. Another fact that may justify the difference found between the groups is that athletes aged 12-14 years aim at professionalization more than 15-17-year-olds, owing to the stages of development [29]. On the other hand, the similarity between the aspects related to intrinsic motivation disagrees with studies of the area that demonstrate an increase of intrinsic motivation with the time of practice and an increase of deliberate practice [8]. Probably, the differ- 
N.P. Souza, H.O. Castro, J.S. Guimaraes, A.M. Carmo, G.C.T. Costa, Motivational factors for sport

ence found between this and other studies is referred to the reduced opportunities of athletes aged 15-17 years to become professionals. So, when these young people analyse the sporting and social context in which they are placed, they realize their own potential to reach their goals and change their aspirations of life [29], fact that may justify the similarity in the results.

\section{Conclusions}

The presented research provided evidence that the intrinsic reasons for the practice of sports, specifically those related to fun and competence, were considered more important for the search and stay of young athletes, aged 12-17 years, in the practice of soccer; extrinsic reasons also influenced their decisions, though on a smaller scale. Thus, in an indirect way, it is possible to verify that intrinsic motivation becomes fundamental for the adhesion to sport, specifically soccer.

However, some limitations must be recognized in this work, such as the influence of parents and some socio-cultural aspects, as well as the restriction referring to the male sex.

Among the practical implications of the study, there is the opportunity for coaches to support their training with the knowledge about the reasons that lead the athletes to practise soccer, that is, mainly fun. At the same time, coaches should choose, modify, and adapt the teaching models so that the training is more enjoyable and provides competence for soccer.

\section{Disclosure statement}

No author has any financial interest or received any financial benefit from this research.

\section{Conflict of interest}

The authors state no conflict of interest.

\section{References}

1. Prichard A, Deutsch J. The effects of motivational climate on youth sport participants. Phys Educator. 2015; 72(5):200-214; doi: 10.18666/TPE-2015-V72-I5-6999.

2. Henriksen K, Stambulova N, Roessler KK. Holistic approach to athletic talent development environments: a successful sailing milieu. Psychol Sport Exerc. 2010; 11(3):212-222; doi: 10.1016/j.psychsport.2009.10.005.

3. Jewett R, Sabiston CM, Brunet J, O’Loughlin EK, Scarapicchia T, O'Loughlin J. School sport participation during adolescence and mental health in early adulthood. J Adolesc Health. 2014;55(5):640-644; doi: 10.1016/j.jadohealth.2014.04.018.

4. Fraser-Thomas JL, Côté J, Deakin J. Youth sport programs: an avenue to foster positive youth development.
Phys Educ Sport Pedagogy. 2005;10(1):19-40; doi: 10.1080/1740898042000334890.

5. Bruner MW, Eys MA, Wilson KS, Côté J. Group cohesion and positive youth development in team sport athletes. Sport Exerc Perform Psychol. 2014;3(4):219227; doi: 10.1037/spy0000017.

6. Johnston J, Harwood C, Minniti AM. Positive youth development in swimming: clarification and consensus of key psychosocial assets. J Appl Sport Psychol. 2013; 25(4):392-411; doi: 10.1080/10413200.2012.747571.

7. Clancy RB, Herring MP, Campbell MJ. Motivation measures in sport: a critical review and bibliometric analysis. Front Psychol. 2017;8:348; doi: 10.3389/fpsyg.2017.00348.

8. Vink K, Raudsepp L, Kais K. Intrinsic motivation and individual deliberate practice are reciprocally related: evidence from a longitudinal study of adolescent team sport athletes. Psychol Sport Exerc. 2015;16(3):1-6; doi: 10.1016/j.psychsport.2014.08.012.

9. Ryan RM, Deci EL. Self-determination theory and the facilitation of intrinsic motivation, social development, and well-being. Am Psychol. 2000;55(1):68-78; doi: 10.1037/0003-066X.55.1.68.

10. Pulido JJ, Sánchez-Oliva D, Leo FM, Matos S, GarcíaCalvo T. Effects of an interpersonal style intervention for coaches on young soccer players' motivational processes. J Hum Kinet. 2017;59:107-120; doi: 10.1515/ hukin-2017-0151.

11. MacDonald DJ, Côté J, Eys M, Deakin J. The role of enjoyment and motivational climate in relation to the personal development of team sport athletes. Sport Psychol. 2011;25(1):32-46; doi: 10.1123/tsp.25.1.32.

12. Peachey JW, Cohen A, Musser A. 'A phone call changed my life': exploring the motivations of sport for development and peace scholars. J Sport Develop. 2016;4(7): $58-70$.

13. Leyton M, Batista M, Lobato S, Aspano MI, Jiménez R. Application of two intervention programs in order to optimize motivation and to improve eating habits in adult and elderly women. J Hum Kinet. 2017;59:131142; doi: 10.1515/hukin-2017-0153.

14. Verardi CEL, Freitas VL, Maffei WS, Hirota VB, De Marco A. Sports performance: a reflection on the startup and the development of Brazilian soccer players. J Phys Educ Sport. 2016;16(2):297-300; doi: 10.7752/ jpes.2016.02047.

15. Tamminen KA, Braun C. Psychological considerations of adolescents in sport and performance. Oxford Research Encyclopedia of Psychology. Oxford University Press; 2017; doi: 10.1093/acrefore/9780190236557. 013.178.

16. Amorose AJ, Anderson-Butcher D, Newman TJ, Fraina M, Iachini A. High school athletes' self-determined motivation: the independent and interactive effects of coach, father, and mother autonomy support. Psychol Sport Exerc. 2016;26:1-8; doi: 10.1016/j.psychsport. 2016.05.005. 
17. Hendry DT, Crocker PRE, Hodges NJ. Practice and play as determinants of self-determined motivation in youth soccer players. J Sports Sci. 2014;32(11):1091-1099; doi: 10.1080/02640414.880792.

18. Telford RM, Telford RD, Olive LS, Cochrane T, Davey R. Why are girls less physically active than boys? Findings from the LOOK longitudinal study. PLoS One. 2016; 11(3):e0150041; doi: 10.1371/jounal.pone.0150041.

19. Forsman H, Blomqvist M, Davids K, Liukkonen J, Konttinen N. Identifying technical, physiological, tactical and psychological characteristics that contribute to career progression in soccer. Int J Sports Sci Coach. 2016;11(4): 505-513; doi: 10.1177/1747954116655051.

20. Albuquerque MR, Lopes MC, de Paula JJ, Faria LO, Pereira ET, da Costa VT. Cross-cultural adaptation and validation of the MPAM-R to Brazilian Portuguese and proposal of a new method to calculate factor scores. Front Psychol. 2017;8:261; doi: 10.3389/fpsyg.2017.00261.

21. Côté J, Erickson K. Diversification and deliberate play during the sampling years. In: Baker J, Farrow D (eds.), Routledge handbook of sport expertise. London: Routledge; 2015; 305-316.

22. Côté J, Murphy-Mills J, Abernethy B. The development of skill in sport. In: Hodges N, Williams AM (eds.), Skill acquisition in sport: research, theory and practice. New York: Routledge; 2012; 269-286.

23. Ericsson KA, Nandagopal K, Roring RW. Toward a science of exceptional achievement: attaining superior performance through deliberate practice. Ann N Y Acad Sci. 2009;1172:199-217; doi: 10.1196/annals.1393.001.

24. Fry MD, Gano-Overway LA. Exploring the contribution of the caring climate to the youth sport experience. J Appl Sport Psychol. 2010;22(3):294-304; doi: 10.1080/ 10413201003776352.

25. Harwood CG, Knight CJ. Parenting in youth sport: a position paper on parenting expertise. Psychol Sport Exerc. 2015;16(Pt 1):24-35; doi: 10.1016/j.psychsport. 2014.03.001.

26. Bergeron MF, Mountjoy M, Armstrong N, Chia M, Côté J, Emery CA, et al. International Olympic Committee consensus statement on youth athletic development. Br J Sports Med. 2015;49(13):843-851; doi: 10.1136/ bjsports-2015-094962.

27. Lunde C, Gattario KH. Performance or appearance? Young female sport participants' body negotiations. Body Image. 2017;21:81-89; doi: 10.1016/j.bodyim.2017. 03.001.

28. Cordes M, Vocks S, Düsing R, Waldorf M. Effects of the exposure to self- and other-referential bodies on state body image and negative affect in resistance-trained men. Body Image. 2017;21:57-65; doi: 10.1016/j.bodyim. 2017.02.007.

29. Delci EL, Ryan RM. Motivation, personality, and development within embedded social contexts: an overview of self-determination theory. The Oxford Handbook of Human Motivation. Oxford University Press; 2012; doi: 10.1093/oxfordhb/9780195399820.013.0006. 